\title{
Avaliação do cumprimento da NR-18 em função do porte de obra residencial e proposta de lista de verificação da NR-18
}

\author{
Evaluation of compliance to NR-18 according to house- \\ building project size and proposal of NR-18 checklist
}

\section{Marcelo Fabiano Costella \\ Franciele Cristina Junges \\ Silvio Edmundo Pilz}

\section{Resumo

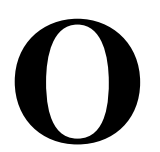

presente trabalho investiga as reais condições dos ambientes de trabalho da indústria da construção, tendo em vista os problemas relacionados à segurança do trabalho nos canteiros de obras. Formulou-se a hipótese de haver discrepância no grau de cumprimento da NR-18 em obras de diferentes portes (pequena, média e grande). Baseado em uma lista de verificação do grau de cumprimento dos requisitos da NR-18, foram avaliados 115 canteiros de obra na cidade de Chapecó - SC. Para cada item da lista de verificação foi atribuída uma nota e, após compilar as informações, estas foram avaliadas conforme os objetivos da pesquisa. Fez-se uma análise crítica para os cinco piores e os cinco melhores itens observados para as obras pequenas, médias e grandes. Analisando-se os resultados é possível afirmar que há uma diferença significativa de aplicação da NR-18 nos diferentes portes de obras, sendo que as obras de grande porte obtiveram uma média final $(6,47)$ significativamente superior em relação às obras pequenas $(1,97)$. Desta forma, foi corroborada a hipótese formulada, podendo se atribuir este resultado a diversos fatores, entre os quais a falta de habilidades gerenciais de segurança e saúde do trabalho nas pequenas empresas. Outra contribuição deste artigo foi a proposta de uma nova lista de verificação para avaliar o grau de cumprimento da NR-18 nos canteiros de obra.

Palavras-chave:Segurança no trabalho. Grau de cumprimento da NR-18. Listas de verificação.

\footnotetext{
Abstract

This research work investigates the real conditions of working environments in the construction industry, considering problems related to occupational safety in construction sites. The hypothesis that the degree of compliance to NR-18

(Brazilian Regulation for Occupational Safety and Health at Construction sites) varies according to project size (small, medium, and large) was formulated. Based on a check-list for verifying the compliance to NR-18 requirements, 115 construction sites from Chapecó, State of Santa Catarina, were evaluated. A score was given for each item of the check-list, and, after processing the data, an analysis was made according to the research objectives. A critical analysis of the five worst and the five best items for small, medium and large construction sites. The results indicated that the degree of compliance to NR-18 depends on the size of the construction site. Large sites had an average degree of compliance (6.47) significantly higher than small sites (1.97), corroborating the hypothesis formulated at the beginning of this investigation. This difference can be explained by several factors, among which stands out the lack of safety and health management skills in small companies. Another contribution of this investigation was the proposal of a new NR-18 check-list to assess construction sites.

Keywords: Occupational safety. Degree of compliance to NR-18. Check-list.
}

Marcelo Fabiano Costella Universidade Comunitária da Região de Chapecó Chapecó - SC - Brasil

Franciele Cristina Junges Universidade Comunitária da Região de Chapecó Chapecó - SC - Brasil

Silvio Edmundo Pilz Universidade Comunitária da Região de Chapeco Chapecó - SC - Brasil

Recebido em 31/03/14 Aceito em 24/07/14

COSTELLA, M. F.; JUNGES, F. C.; PILZ, S. E. Avaliação do cumprimento da NR-18 em função do porte de obra residencial e proposta de lista de verificação da NR-18. Ambiente Construído, Porto Alegre, v. 14, n. 3, p. 87-102, jul./set. 2014.

ISSN 1678-8621 Associação Nacional de Tecnologia do Ambiente Construído. 


\section{Introdução}

Ao analisar os acidentes na construção, estudos nacionais e internacionais (CAMINO LÓPEZ et al., 2008; LING; LIU; WOO,2009) destacam a construção como uma das maiores geradoras de acidentes do trabalho. Em uma análise recente, que contribui para compilar as contribuições dos demais estudos, Hinze, Thurman e Wehle (2013) apresentam as taxas de acidentes na construção civil americana, as quais diminuíram de 14,3 acidentes por 100.000 trabalhadores em 1988 para 4,3 em 2010. Entretanto, os dados não apresentam nenhuma indicação de quais fatores contribuíram para essa significativa melhoria. Hinze, Thurman e Wehle (2013) exemplificam que a Occupational Safety and Health Administration (OSHA) promoveu, ao longo dos últimos 35 anos, mudanças significativas na legislação na área de escavações de trincheiras, prevenção de quedas e içamento de estruturas, o que, talvez, tenha contribuído para a diminuição dos índices, mas pode ser que o aumento dos custos de saúde e dos seguros tenha levado os construtores a aumentar os esforços para a melhoria do desempenho de segurança.

Os elevados números de acidentes de trabalho ocorridos no setor de construção civil trazem à tona a questão do cumprimento das normas de segurança, como, por exemplo, da Norma Regulamentadora n. 18 (NR-18), específica para a indústria da construção (BRASIL, 2013a). Para Abudayyeh et al. (2006) e Waehrer et al. (2007), as empresas costumam estabelecer políticas de segurança e seus procedimentos de acordo com a legislação pertinente, entretanto a maioria dos acidentes e lesões na construção é resultado direto do não cumprimento dos procedimentos estabelecidos pela própria empresa. Além disso, para Niza, Silva e Lima (2008), a gestão do programa de prevenção de acidentes passa pela capacitação dos trabalhadores para evitar discrepâncias em concepções e interpretações dos respectivos procedimentos.Nessa linha de pensamento, Gambatese, Behm e Rajendran (2008) afirmam que a combinação das características de alto risco de acidentes e baixo nível educacional dos trabalhadores da construção necessita o estabelecimento de medidas preventivas que minimizem esses fatores, antes que os acidentes ocorram.

No entanto, a diversidade das obras, a falta de técnicos especializados dentro das empresas, o caráter temporário das instalações de produção, a rotatividade da mão de obra e o emprego de equipes terceirizadas são fatores que dificultam a criação e a manutenção da segurança nos canteiros.
Aliado a isso, buscou-se saber qual é o grau de cumprimento da NR-18 em canteiros de obra de diferentes portes.

Diversas pesquisas revelam que as pequenas empresas de construção têm uma taxa de acidentes mais elevada quando comparadas às grandes empresas de construção em vários países. As causas desse desempenho inferior de segurança e saúde no trabalho (SST) das pequenas empresas estão ligadas à negligência da gestão de SST e à falta de treinamento dos trabalhadores(HINZE; PEDERSEN; FREDLEY, 1998; SAWACHA; NAOUM; FONG, 1999; HUANG; HINZE, 2003;FABIANO; CURRÓ; PASTORINO, 2004; AKSORN; HADIKUSUMO, 2008).

Além disso, existem evidências de que as grandes empresas de construção possuem um desempenho de segurança superior às pequenas empresas(MCVITTIE; BANIKIN BROCKLEBANK, 1997;HINZE; GAMBATESE, 2003; FERNANDEZ-MUNIZ; MONTES-PEÓN; VÁSQUEZ-ORDÁS, 2009), tal qual este artigo objetiva demonstrar no que se refere ao cumprimento da NR-18.

Para essa verificação, fez-se uso de controle específico para canteiros de obras da construção civil, porém em virtude de ele ter sido publicado em 2010 e até os dias de hoje não ter sofrido alteração é que se propôs uma nova lista de verificação da NR-18, a qual está devidamente adequada às últimas portarias da norma.

\section{Norma Regulamentadora $\mathrm{n}^{\circ} 18$}

Entre as normas regulamentadores existe uma específica para a indústria construção no Brasil, a NR-18 - Condições e meio ambiente de trabalho na indústria da construção (BRASIL, 2013a). Para Gonçalves (2008), a atual norma regulamentadora de segurança e saúde na indústria da construção civil possui uma sistematização mais oportuna que a anterior, sendo bastante detalhada nos aspectos técnicos e dotada de mecanismos próprios tendentes a uma adequação mais rápida dos dispositivos normativos. Mas ainda apresenta conceitos incompatíveis com normas regulamentadoras recentes e demais instrumentos normativos.

Atualmente, a NR-18 encontra-se em processo de revisão. As alterações propostas estão relacionadas à correção de textos, buscando eliminar repetições desnecessárias, e também à compatibilização dos itens da norma com conceitos e dispositivos de outras normas regulamentadoras recentes. 


\section{Listas de verificação da NR-18}

Diversas pesquisas,as quais têm seus resultados discutidos neste artigo, utilizaram listas de verificação nos canteiros de obras da construção civil (SAURIN, 1997; ROCHA, 1999; SAURIN; LANTELME; FORMOSO, 2000; PANDOLFO et al., 2007; MALLMANN, 2008; ALVARENGA, 2009; CHAGAS, 2009; COSTELLA; GALINA, 2010), contudo todas elas avaliaram o grau de cumprimento da norma de maneira geral ou propuseram listas de verificação, diferentemente desta pesquisa, que avalia a aplicação dos requisitos da NR-18 de acordo com os diferentes portes de obras (pequena, média e grande), o que se considera o diferencial deste artigo, além da proposta de uma nova lista de verificação.

Rocha (1999) desenvolveu uma lista de verificação da NR-18 para que as empresas do setor pudessem cumprir os tópicos da norma e se autoavaliar. Seu objetivo principal era traçar um perfil do cumprimento da norma nos canteiros de obras abordados. Depois de aplicadas as listas de verificação, os resultados demonstraram baixo desempenho das empresas pesquisadas. Com base nisso, o autor assegurou que a segurança na construção civil do país está aquém do desejado, visto que a média nacional para os canteiros analisados foi de 5,1 .

Segundo Saurin, Lantelme e Formoso (2000), em 1998, sete universidades brasileiras (UFRGS, UPF, UFSM, UFBA, UEFS, UNIFOR e CEFET/PB) iniciaram uma pesquisa com o intuito de buscar subsídios para o aperfeiçoamento da NR-18. Para tanto, pesquisadores aplicaram o checklist (lista de verificação) em 79 canteiros de edificações residenciais e comerciais em sete cidades do país. Ao final, foi possível concluir que determinadas exigências da norma são mais cumpridas do que outras, e atribuíram as causas do não cumprimento de alguns requisitos ao caráter prescritivo de algumas exigências, ao papel secundário destinado à segurança no trabalho no gerenciamento das empresas, à falta de conhecimento da norma e, em alguns casos, às dificuldades técnicas e custo de equipamentos. Em relação aos resultados, entre as sete cidades pesquisadas, a média nas capitais (João Pessoa, Fortaleza, Salvador, Porto Alegre) ficou em 6,1, e nas demais cidades (Santa Maria, Passo Fundo, Feira de Santana), em 4,1. Nessa mesma linha, a pesquisa realizada por Pandolfo et al. (2007) em uma cidade do interior do Rio Grande do Sul obteve baixo resultado de cumprimento da NR-18, com média de 2,31.

Estudos mais recentes aplicados com uma lista de verificação de 201 itens, atualizada por Mallmann
(2008), foram conduzidos em Porto Alegre (MALLMANN, 2008), Belém (ALVARENGA, 2009) e Aracaju (CHAGAS, 2009), totalizando 74 canteiros de obras. Esses estudos relataram melhora no cumprimento da NR-18 em relação ao estudo-base de Saurin, Lantelme e Formoso (2000). Apesar de os estudos não representarem o universo de obras das localidades analisadas, a média nas três capitais pesquisadas aumentou de 6,1 para 6,9 .

Com base na lista de verificação proposta por Saurin, Lantelme e Formoso (2000), Costella e Galina (2010) sugeriram modificações em virtude de mudanças ocorridas na norma. Contudo, apesar de esta lista ter sido utilizada para avaliar o grau de cumprimento da NR-18 em função do porte de obra apresentado neste artigo, a proposta de alteração foi feita há três anos, e em meio a este tempo outras sete novas portarias da norma foram publicadas: Portaria n. 201 (BRASIL, 2011b), Portaria n. 224 (BRASIL, 2011c), Portaria n. 237 (BRASIL, 2011d),Portaria n.254 (BRASIL, 2011e), Portaria n. 296 (BRASIL, 2011f), Portaria n. 318 (BRASIL, 2012) e Portaria n. 644 (BRASIL, 2013b). Em decorrência disso é que se propôs uma nova proposta de lista de verificação da NR-18.

Resultante das alterações e das novas exigências da norma de Condições e Meio Ambiente de Trabalho na Indústria da Construção, propôs-se uma lista de verificação em que se apresenta o aperfeiçoamento de alguns aspectos da norma expostos de maneira autoexplicativa, sem a necessidade de grande experiência ou conhecimento aprofundado na NR-18 para sua utilização.

\section{Procedimentos metodológicos}

\section{Grau de cumprimento da NR-18}

Para verificar as condições de segurança e saúde no que diz respeito ao cumprimento da NR-18 foram realizadas visitas nos canteiros de obras eprocedeu-se a um levantamento de informações por meio da lista de verificação. Os dados levantados foram compilados, analisados e depois selecionados, conforme o interesse da pesquisa, sempre levando em consideração o cumprimento da NR-18. Além disso, fez-se acompanhamento em obras residenciaisde diferentes portes.

A partir das visitas realizadas em 115 canteiros de obra por alunos da graduação em Engenharia Civil nos últimos 2 anos, foram coletados dados da lista de verificação da NR-18 (COSTELLA; GALINA, 2010) nas obras selecionadas para o estudo, as quais foram selecionadas a partir de listas de 
Anotação de Responsabilidade Técnica(ART), de maneira aleatória, e houve uma ótima aceitação. As empresas, em um primeiro momento, pensavam que se tratava de uma fiscalização da SuperintendênciaRegional do Trabalho, mas, após explicação dos pesquisadores de que se tratava de pesquisa acadêmica, costumavam permitir o estudo, com raras exceções.

A lista de verificação utilizada possui três alternativas para cada item: SIM, NÃO e NÃO SE APLICA. Os itens assinalados com SIM representam o cumprimento da norma; os itens assinalados com NÃO representam o descumprimento da norma; e os itens assinalados com NÃO SE APLICA representam que o item não era necessário naquele estágio da obra ouna obra. Durante as visitas aos canteiros também foram registrados, com fotografias, exemplos de boas e más práticas de segurança do trabalho.

Ao todo foram avaliadas 29 obras de pequeno porte, 33 de médio porte, e 53 canteiros de grande porte, totalizando 115 obras. A classificação foi desenvolvida para contemplar as características de obras executadas na região. As obras de pequeno porte abrangiam as residências unifamiliares de até dois pavimentos (máximo de $250 \mathrm{~m}^{2}$ ), as obras de médio porte, edifícios de até quatro pavimentos, com máximo de $2.000 \mathrm{~m}^{2}$, e as obras de grande porte, edificações decinco a quatorze pavimentos. Nas obras pesquisadas, não foi possível, nem houve o objetivo de classificar o tamanho das empresas construtoras.

As visitas variavam conforme o tamanho da obra, em média 30 min para obras de pequeno porte, 60 min para obras de médio porte e 120 min para obras de grande porte.

\section{Compilação dos dados}

A partir de planilhas criadas no Microsoft Excel ${ }^{\circledR}$ foi feita a compilação geral dos dados, os quais foram agrupados de acordo com o porte da obra e, na sequência, do ano de observação, no caso obras de 2010, 2011 e 2012. Em seguida, as informações coletadas foram separadas por grupos (áreas de vivência, armações de aço, elevadores, etc.), contendo itens da lista de verificação.

\section{Análise dos dados}

Feita a compilação dos dados, iniciou-se a análise deles, quandose avaliou a nota referente a cada item da norma. Tal nota é gerada por fórmula fixada no Microsoft Excel $^{\circledR}$, dada pelo somatório de SIM dividido pelo somatório de SIM e NÃO. Os resultados da pesquisa indicam o número de obras que foram consideradas para a análise das avaliações, a quantidade de dados que foram utilizados e a média aritmética das notas. Assim, as notas podem ser representadas de duas formas: na forma decimal (0 a 10) ou na forma percentual (0\% a $100 \%)$.

De acordo com o porte de obra, foram analisados e avaliados individualmente os 36 tópicos que compõem a lista de verificação da NR-18, visto que os itens "redes de segurança" e "ancoragem" não foram analisados nos canteiros de obras pesquisados. Em seguida, os resultados foram apresentados no seguinte formato: os cinco tópicos mais bem pontuados e os cinco piores. Como forma de refinar a amostra dos itens avaliados da NR-18, optou-se por desconsiderar aqueles que tivessem o índice de obras analisadas menor ou igual a $25 \%$ do total de canteiros pesquisados para cada porte de obra, ou seja, não foram considerados os resultados dos itens em que havia muitas respostasNÃO SE APLICA.

A partir das médias obtidas em cada porte de obra para todos os itens analisados, foi feita comparação do grau de cumprimentoentre os diferentes portes de obras residenciais.

\section{Proposta de uma nova lista de verificação}

Ao longo da pesquisa, trabalhando-se com a lista de verificação proposta por Costella e Galina (2010), foram observados alguns pontos falhos, outros desnecessáriose desatualizações com as últimas portarias publicadas na norma NR-18. Devido a isso se propuseram mudanças, sendo feita uma nova lista de verificação para os requisitos da norma específica da indústria da construção.

A estruturação da lista de verificação foi mantida. Apenas em função da grande extensão da norma, optou-se por selecionar os principais tópicos com alto índice de aplicabilidade, assim a lista de verificação final foi dividida em 16 tópicos. Apesar de a NR-18 possuir 750 itens, a lista de verificação adotada possui apenas 249. Em função disso, alguns itens relatam mais de uma exigência, como, por exemplo, o item C.3.1 (Estálocalizado próximo à entrada da obra, está em bom estado deconservação e tem iluminação natural e/ou artificial), no qual será considerado SIM se se cumprirem todos os aspectos listados. Assim, se um deles não for cumprido, a resposta será NÃO.

Junto a alguns itens existe a explicação de sua obrigatoriedade nos canteiros de obras, por exemplo, instalações sanitárias, exigidas para todas as obras, independentemente do tamanho do canteiro ou do número de funcionários, e elevador 
de passageiros, obrigatório para edifícios com mais de oito pavimentos.

\section{Apresentação e discussão dos resultados}

\section{Avaliação do grau de cumprimento da NR-18}

\section{Avaliação quantitativa dos dados coletados}

Os dados coletados em todas as obras referentes a cada item da lista de verificação estão apresentados na Tabela 1, que descreve o número de obras consideradas e a respectiva média geral dos portes de obra (pequena, média e grande).
Os diferentes portes de obras apresentaram características distintas entre os itens analisados. Para quase todas as seções avaliadas da lista de verificação, a média geral para cada tamanho de obra aumentou na direção proporcional ao porte de obra, com exceção somente das "escadas de mão e provisórias", em que a média das obras de médio porte $(4,13)$ foi inferior à das obras pequenas $(4,95)$. Em função dos resultados globais, com a média geral das obras de pequeno porte (somente $1,97)$ e das obras de grande porte $(6,47)$, verificase o maior comprometimento nas grandes obras em cumprir os requisitos estabelecidos na norma referente às condições no trabalho na construção civil.

Tabela 1 -Médias de todas as atividades executadas por porte de obra

\begin{tabular}{|c|c|c|c|c|c|c|}
\hline Descrição do tópico & \multicolumn{2}{|c|}{ Pequeno porte } & \multicolumn{2}{|c|}{ Médio porte } & \multicolumn{2}{|c|}{ Grande porte } \\
\hline A - Tapume e galerias & 29 & 0,69 & 33 & 3,16 & 53 & 6.02 \\
\hline B - Ordem e limpeza & 29 & 1,72 & 33 & 4,65 & 53 & 7,42 \\
\hline C.1 - Instalações sanitárias & 29 & 1,74 & 33 & 5,99 & 53 & 7,73 \\
\hline C. 2 - Instalações móveis & 2 & 5,00 & 6 & 5,67 & 9 & 6,85 \\
\hline C. 3 - Vestiário & 29 & 0,49 & 33 & 4,14 & 53 & 6,55 \\
\hline C.4 - Alojamento & 3 & 7,49 & 5 & 7,62 & 9 & 8,47 \\
\hline C. 5 - Local para refeições & 29 & 0,76 & 33 & 5,73 & 53 & 7,73 \\
\hline C.6 - Área de lazer & 3 & 3,33 & 13 & 10,00 & 27 & 10,00 \\
\hline C.7 - Fornecimento de água potável & 29 & 2,07 & 33 & 6,11 & 53 & 6,76 \\
\hline D - Demolição & 1 & 0,00 & 3 & 2,78 & 1 & 6,67 \\
\hline E - Escavações, fundações, desmonte de rochas & 3 & 1,11 & 1 & 10,00 & 8 & 4,20 \\
\hline F - Serra circular e central de carpintaria & 12 & 2,05 & 18 & 5,82 & 34 & 6,56 \\
\hline $\mathrm{G}$ - Armação de aço & 10 & 1,22 & 17 & 3,83 & 39 & 5,08 \\
\hline H.1 - Corrimãos das escadas & 9 & 0,00 & 29 & 3,42 & 46 & 7,36 \\
\hline H.2 - Escadas de mão e provisórias & 22 & 4,95 & 31 & 4,13 & 43 & 5,55 \\
\hline H.3 - Poço do elevador & - & - & - & - & 47 & 6,21 \\
\hline H.4 - Proteção contra qued & 7 & 0,00 & 14 & 1,24 & 38 & 4,17 \\
\hline H.5 - Aber & 6 & 0,00 & 15 & 2,00 & 38 & 5,00 \\
\hline H.6 - Plataformas de proteção & - & - & - & - & 37 & 5,82 \\
\hline H.7 - Redes de segurança & - & - & - & - & - & - \\
\hline H.8 - Andaimes susper & 1 & 0,00 & 4 & 5,16 & 11 & 7,62 \\
\hline H.9 - Andaimes facha & 1 & 2,00 & 4 & 4,50 & - & - \\
\hline H.10 - An & 15 & 4,44 & 18 & 6,25 & 26 & 6,15 \\
\hline H.11 - Cadeira suspensa & - & - & - & - & 2 & 8,75 \\
\hline H.12 - Ancoragem & - & - & - & - & - & - \\
\hline I. 1 - Torre do elevad & - & - & - & - & 15 & 8,53 \\
\hline I. 2 - Plataforma do e & - & - & - & - & 15 & 9,36 \\
\hline I. 3 - Posto do guincheiro & - & - & - & - & 15 & 6,93 \\
\hline $\mathrm{J}$ - Elevador de passageiros & - & - & - & - & 8 & 6,06 \\
\hline $\mathrm{K}$ - Grua & - & - & - & - & 7 & 6,20 \\
\hline L - Elevador & - & - & - & - & 5 & 10,00 \\
\hline M - Servi & 5 & 0,00 & 5 & 0,67 & 3 & 4,44 \\
\hline $\mathrm{N}$ - Instalaçõ & 27 & 2,52 & 33 & 4,20 & 39 & 8,36 \\
\hline $\mathrm{O}$ - Máquinas, equipamer & 27 & 4,70 & 32 & 5,55 & 51 & 7,30 \\
\hline $\mathrm{P}$ - Equipamento de proteçã & 29 & 1,35 & 33 & 5,33 & 53 & 8,06 \\
\hline $\mathrm{Q}$ - Armazenamento e esto & 29 & 5,25 & 32 & 5,96 & 53 & 7,16 \\
\hline $\mathrm{R}$ - Proteção contra incêndio & 29 & 0,19 & 33 & 1,69 & 53 & 3,18 \\
\hline $\mathrm{S}$ - Sinalização de segurança & 29 & 0,09 & 33 & 2,91 & 53 & 4,17 \\
\hline Média geral de todas as atividades executadas & \multicolumn{2}{|c|}{1,97} & \multicolumn{2}{|c|}{4,56} & \multicolumn{2}{|c|}{6,47} \\
\hline
\end{tabular}


Em relação a outros estudos realizados no Brasil (ROCHA, 1999; SAURIN; LANTELME; FORMOSO, 2000; PANDOLFO et al., 2007; MALLMANN, 2008; ALVARENGA, 2009; CHAGAS, 2009), a média de cumprimento da NR18 das obras de grande porte manteve-se em nível intermediário em relação aos demais estudos, sendo superior aos estudos anteriores a 2007, porém inferior aos estudos de 2008 e 2009. Entretanto, as obras de pequeno porte tiveram desempenho inferior em todos os estudos mencionados.

Nas obras de pequeno porte, dos 29 canteiros considerados, foi possível analisar 27 dos 38 itens da lista de verificação utilizada. Baseado na média geral final $(1,97)$, é possível afirmar que as obras unifamiliares pouco cumprem as diretrizes da NR18.

A média final das obras de médio porte quase alcançou $50 \%$ de cumprimento da norma, ficando com 4,56 de nota pelo desempenho. Neste tamanho de obra foi possível verificar os mesmos 27 itens da lista de verificação base das obras pequenas, mas se conseguiu trabalhar com uma amostra maior de obras, no caso, 33 canteiros.

Para as obras de grande porte, os 35 itens analisados resultaram numa média geral final igual a 6,47. Tal avaliação é resultado das melhores condições desses canteiros de trabalho, e prova disso é que apenas cinco itens ("escavações, fundações e desmonte de rochas", "proteção contra queda no perímetro dos pavimentos", "serviços em telhados e cobertura", "proteção contra incêndio" e "sinalização de segurança") obtiveram nota geral inferior a 5,0, enquanto nas obras de pequeno e médio porte a média foi inferior a 5,0.

Os “tapumes e galerias” possuíram porcentagem de cumprimento igual a $6,9 \%$ (nota 0,69 ) para obras pequenas, $31,6 \%$ (nota 3,16 ) para obras médias, e 60,2\% (nota 6,02) para obras de grande porte. Com esses valores se percebe que a obrigatoriedade em construir barreiras visando impedir o acesso de pessoas estranhas aos serviços é desconsiderada nas obras menores, ou então os isolamentos existentes não possuem altura mínima predeterminada $(2,20 \mathrm{~m})$.

A "ordem e limpeza" dos canteiros nos diferentes portes de obra também é um item a ser discutido, uma vez que novamente as obras pequenas deram pouca importância a esse quesito, principalmente pelo fato de não haver local adequado para a coleta de entulho. Quanto ao "armazenamento e estocagem de materiais", as diferenças entre os valores foram menores, sendo 52,5\% para obras pequenas, $59,6 \%$ para as obras médias, e $71,6 \%$ para as obras grandes.
As "máquinas, equipamentos e ferramentas diversas" apresentaram algumas inconformidades, sobretudo porque as partes móveis dos motores e transmissões e as partes perigosas das máquinas não estavam devidamente protegidas, além de o ambiente de trabalho desses equipamentos não estar adequado. Para esta observação, as médias dos portes de obra variaram de 4,7 a 7,3.

Alguns dos itens das "áreas de vivência", como as "instalações sanitárias", "vestiário" e "local para as refeições", merecem destaque pelas divergências encontradas diante do cumprimento da norma. Nos três tipos de obras analisadas tais itens possuem piores situações nas obras de pequeno porte. Os principais motivos do descumprimento da norma estão atrelados à inexistência desses equipamentos, à precariedade dos utensílios utilizados e à higiene e conservação dos ambientes de trabalho. O "fornecimento de água potável" também foi um ponto falho. Houve obras em que não existiam refrigeradores, em certos canteiros os funcionários compartilhavam o copo em que bebiam água, e também houve relatos de que o próprio trabalhador era quem levava o refresco, para se manter hidratado.

As "instalações elétricas", pelo fato de serem provisórias, em muitos casos eram feitas de forma precária. Somente nas obras de grande porte é que foi possível observar disjuntores individuais para cada circuito de derivação, com a respectiva identificação. Em muitos canteiros deparou-se com fios desencapados e/ou dispostos em locais úmidos, onde havia constante passagem de pessoas e materiais. As médias deste item variaram de 2,5 (pequena) a 8,3 (grande).

Pode-se dizer que a atenção dada ao uso dos "equipamentos de proteção individual" (EPI) varia muito das obras de maior porte para as de pequeno porte (médias de 8,1 a 1,3). Talvez em consequência da maior fiscalização dos grandes canteiros, os trabalhadores usem os equipamentos. Já nas obras menores, segundo a NR-6 (BRASIL, 2011a), o dever dos empregadores em colocar à disposição de seus empregados os EPIs não é cumprido, ou, então, os empregados não cumprem com sua obrigação em usar os EPIs e não há cobrança para com estes em usá-los.

Levando-se em consideração a "proteção contra incêndio", os números da pesquisa indicam que nas obras pequenas $1,9 \%$ dos itens estavam de acordo com a NR-18, nas obras médias $(16,9 \%)$ e nas obras grandes $31,8 \%$ iam de encontro às exigências. Assim, a existência de extintores de incêndio nos diferentes locais de trabalho foi ignorada, e em nenhum caso as equipes de 
operários foram treinadas para o primeiro combate ao fogo.

Quanto à "sinalização de segurança", somente $0,9 \%$ dos 29 canteiros abordados de obras pequenas possuíam locais identificados; nas obras médias $29,1 \%$ cumpriam com a sinalização, tendo em algumas obras poucas placas indicando acessos restritos, locais de apoio (banheiros, almoxarifado, entre outros), alertas da obrigatoriedade do uso de EPIs básicos, etc. As obras de grande porte também não chegaram à metade do cumprimento da norma, obtendo $41,7 \%$ de conformidade com as exigências prescritas.

Importância deve ser dada à média obtida no "elevador de cremalheira",em que, dos 5 analisados nas obras grandes, todos cumpriam com os requisitos da norma, obtendo nota máxima (10). Uma explicação para tal sucessoestáno fato de o uso desse tipo de equipamento ser recente na região e, por isso, apresentar todas as suas partes perfeitamente instaladas e em ótima conservação.

\section{Apresentação e discussão dos dados por porte de obra}

Depois de compilados os dados e analisada a média por porte de obra, separaram-se as informações nasTabelas 2, 3 e 4, cujos critérios de apresentação foram os cinco tópicos mais bem pontuados e os cinco piores. Nestas tabelas se apresenta também o grau de cumprimento dos itens selecionados.

Para as obras de pequeno porte (Tabela 2) considerou-se o grau de cumprimento dos corrimãos das escadas permanentes $(0,0 \%)$, sinalização de segurança $(0,9 \%)$, proteção contra incêndio $(1,9 \%)$, tapumes e galerias $(6,9 \%)$ e armação de aço $(12,2 \%)$ como tendo as piores médias. Muitas dessas obras não possuíam tapumes ao redor do canteiro, não havia sinalizações com indicações dos ambientes, nem placas indicando as saídas de emergência. Raramente se constatou um extintor de incêndio, os locais para armação de aço eram precários, e nas obras que possuíam escadas permanentes estas dificilmente tinham proteção em suas extremidades.

Com os melhores índices de avaliação das obras de pequeno porte estão as instalações elétricas (25,2\%), andaime simplesmente apoiado (44,4\%), máquinas, equipamentos e ferramentas diversas (47,0\%), escadas de mão e provisórias $(49,5 \%)$, e armazenamento e estocagem de materiais $(52,5 \%)$. Percebe-se que o grau de cumprimento dos itens analisados para as obras pequenas é baixo; mesmo os melhores itens selecionados praticamente não chegam a atender a $50 \%$ da norma, ou seja, fica evidenciada a precariedade das condições de segurança e saúde nesse tipo de obra, de modo que itens obrigatórios negligenciam as normas de segurança ditadas.

As obras de médio porte (Tabela 3) apresentam um percentual maior de cumprimento da NR-18 quando comparadas às de pequeno porte. Os itens proteção contra queda no perímetro dos pavimentos $(12,4 \%)$, proteção contra incêndio $(16,9 \%)$, aberturas no piso $(20,0 \%)$, sinalização de segurança $(29,1 \%)$ e tapumes e galerias $(31,6 \%)$, entre todos os requisitos analisados, foram os queobtiverama menor média. As aberturas no piso são um fator de risco, seja pela inexistência de proteção no vão ou, na maior parte dos casos,pelofato de o fechamento do vão ser feito precariamente.

Tabela 2-Itens de maior e menor grau de cumprimento da NR-18 nas obras de pequeno

\begin{tabular}{l|c|c|c}
\hline \multirow{2}{*}{ Descrição do tópico } & \multicolumn{3}{c}{ Obra de pequeno porte } \\
\cline { 2 - 4 } & $\begin{array}{c}\text { Número de obras } \\
\text { consideradas }\end{array}$ & $\begin{array}{c}\text { \% do cumprimento } \\
\text { da NR-18 }\end{array}$ & Média \\
\hline Corrimãos das escadas permanentes & 9 & $0,0 \%$ & 0,00 \\
Sinalização de segurança & 29 & $0,9 \%$ & 0,09 \\
Proteção contra incêndio & 29 & $1,9 \%$ & 0,19 \\
Tapumes e galerias & 29 & $6,9 \%$ & 0,69 \\
Local para refeições & 29 & $7,6 \%$ & 0,79 \\
& & & \\
Instalações elétricas & 27 & $25,2 \%$ & 2,52 \\
Andaime simplesmente apoiado & 15 & $44,4 \%$ & 4,44 \\
Máquinas, equipamentos e ferramentas diversas & 27 & $47,0 \%$ & 4,70 \\
Escadas de mão e provisórias & 22 & $49,5 \%$ & 4,95 \\
Armazenamento e estocagem de materiais & 29 & $52,5 \%$ & 5,25 \\
\hline
\end{tabular}


Tabela 3 - Itens de maior e menor grau de cumprimento da NR-18 nas obras de médio porte

\begin{tabular}{l|c|c|c}
\hline \multirow{2}{*}{ Descrição do tópico } & \multicolumn{3}{c}{ Obra de médio porte } \\
\cline { 2 - 4 } & $\begin{array}{c}\mathbf{N}^{\mathbf{0}} \text { de obras } \\
\text { consideradas }\end{array}$ & $\begin{array}{c}\text { \% do cumprimento } \\
\text { da NR-18 }\end{array}$ & Média \\
\hline Proteção contra queda no perímetro dos pavimentos & 14 & $12,4 \%$ & 1,24 \\
Proteção contra incêndio & 33 & $16,9 \%$ & 1,69 \\
Aberturas no piso & 15 & $20,0 \%$ & 2,00 \\
Sinalização de segurança & 33 & $29,1 \%$ & 2,91 \\
Tapumes e galerias & 33 & $31,6 \%$ & 3,16 \\
& & & \\
Armazenamento e estocagem de materiais & 32 & $59,6 \%$ & 5,96 \\
Instalações sanitárias & 33 & $59,9 \%$ & 5,99 \\
Fornecimento de água potável & 33 & $61,1 \%$ & 6,11 \\
Andaime simplesmente apoiado & 18 & $62,5 \%$ & 6,25 \\
Local para refeições & 29 & $65,2 \%$ & 6,52 \\
\hline
\end{tabular}

Armazenamento e estocagem dos materiais $(59,6 \%)$, instalações sanitárias $\quad(59,9 \%)$, fornecimento de água potável $(61,1 \%)$, andaime simplesmente apoiado $(62,5 \%)$ e local para as refeições $(65,2 \%)$ das obras médias obtiveram as melhores médias, e todos esses itens possuem porcentagem de cumprimento da NR-18 superior a $50 \%$.

Os pontos positivos encontrados no armazenamento e estocagem dos materiais remetem-se à disposição e ao espaço destinado a essa função. Referente às áreas de vivência, nas instalações sanitárias (Figura 1) grande parte das obras visitadas possuía lavatórios, vasos sanitários e mictórios na proporção adequada, bem como o número de chuveiros e o local para as refeições dos canteiros eram, em sua maioria, bem conservados e dotados de equipamentos necessários para aquecer os alimentos.

Já quanto ao fornecimento de água aos trabalhadores pode-se dizer que, apesar de muitas empresas não possuírem bebedouros espalhados pela obra, eram deixados à disposição litros de garrafas pet na geladeira do refeitório, para facilitar a mobilidade. Os andaimes simplesmente apoiados possuíam melhores condições de estabilidade, uma vez que se trabalhava em alturas superiores ao nível do térreo, contudo era preciso ter maior cautela quando próximos aos peitoris das janelas, por exemplo.

Na Tabela 4 encontram-se as piores e as melhores médias das obras de grande porte e o grau de cumprimento dos itens selecionados.

As menores porcentagens de cumprimento da NR18 verificadas nas obras de grande porte referem- se à proteção contra incêndio $(31,8 \%)$, proteção contra queda no perímetro dos pavimentos $(41,7 \%)$, sinalização de segurança $(41,7 \%)$, aberturas no piso $(50,0 \%)$ e armação de aço $(50,8 \%)$. Pode-se atribuir tais médias ao fato de que em locais como a central de carpintaria e almoxarifado não havia extintores de incêndio; alguns contornos dos edifícios encontravam-se desprotegidos sem guarda-corpo (Figura 2); nem todos os ambientes possuíam identificação algumas obras não possuíam placas sinalizando as saídas de emergência; algumas aberturas existentes no piso estavam sem fechamento provisório resistente; e a principal infração cometida na área de armação de aço dizia respeito à falta de proteção na ponta dos vergalhões.

Os principais itens positivos avaliados nas obras de grande porte foram: EPIs $(80,6 \%)$, instalações elétricas $(83,6 \%)$, torre do elevador $(83,5 \%)$, plataforma do elevador $(93,6 \%)$ e área de lazer (100\%). O comprometimento das empresas maiores em relação ao uso dos EPIs é significativo. Pode-se dizer que as instalações elétricas apresentavam boas condições para uso, os fios condutores, na maior parte dos casos, estavam protegidos, e as máquinas e equipamentos elétricos estavam ligados por conjunto plugue e tomada. Em grande parte das construções a torre e a plataforma dos elevadores estavam instaladas e construídas de forma correta e segura. Em se tratando da área de lazer houve grande destaque, uma vez que, apesar de ter havido apenas 9 canteiros de obras com alojamento, onde a área de lazer dos trabalhadores se faz obrigatória, este item de entretenimento foi verificado em 27 obras e obteve nota média máxima de adequação ao estabelecido em norma.

94 Costella, M. F.; Junges, F. C.; Pilz, S. E. 
Figura 1- Instalações sanitárias

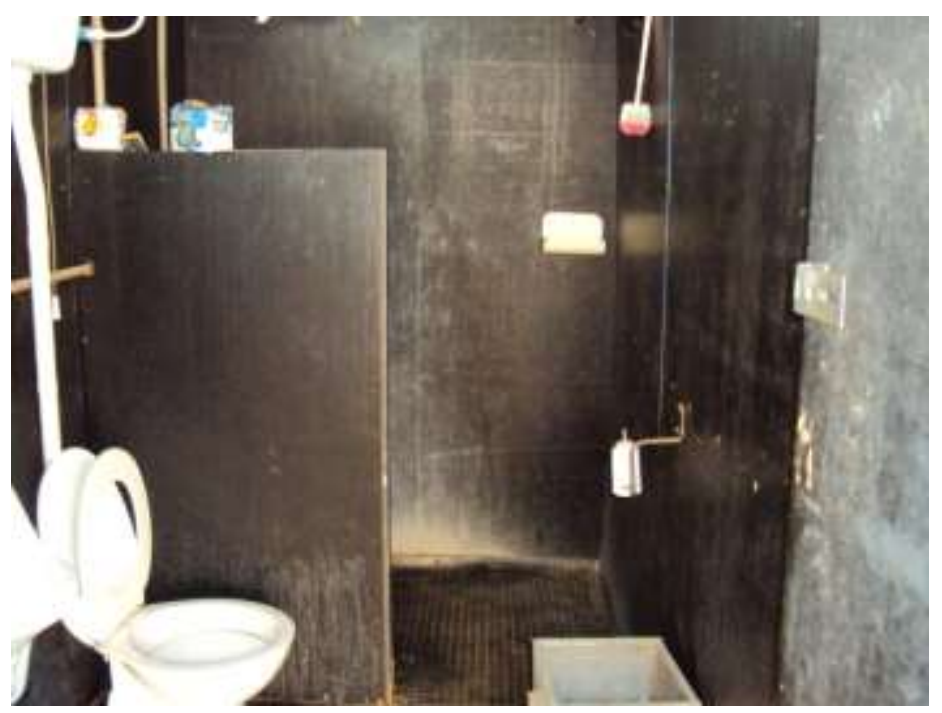

Tabela 4 - Itens de maior e menor grau de cumprimento da NR-18 nas obras de grande porte

\begin{tabular}{l|c|c|c}
\hline \multicolumn{1}{c|}{ Descrição do tópico } & \multicolumn{3}{c}{ Obra de grande porte } \\
\cline { 2 - 4 } & $\begin{array}{c}\mathbf{N}^{\mathbf{0}} \text { de obras } \\
\text { consideradas }\end{array}$ & $\begin{array}{c}\text { \% do cumprimento } \\
\text { da NR-18 }\end{array}$ & Média \\
\hline Proteção contra incêndio & 53 & $31,8 \%$ & 3,18 \\
Proteção contra queda no perímetro dos pavimentos & 38 & $41,7 \%$ & 4,17 \\
Sinalização de segurança & 53 & $41,7 \%$ & 4,17 \\
Aberturas no piso & 38 & $50,0 \%$ & 5,00 \\
Armação de aço & 39 & $50,8 \%$ & 5,08 \\
& & & \\
Equipamento de proteção individual & 53 & $80,6 \%$ & 8,06 \\
Instalações elétricas & 39 & $83,6 \%$ & 8,36 \\
Torre do elevador & 15 & $85,3 \%$ & 8,53 \\
Plataforma do elevador & 15 & $93,6 \%$ & 9,36 \\
Área de lazer & 27 & $100,0 \%$ & 10,00 \\
\hline
\end{tabular}

Figura 2- Inexistência de proteção eficaz na periferia da edificação

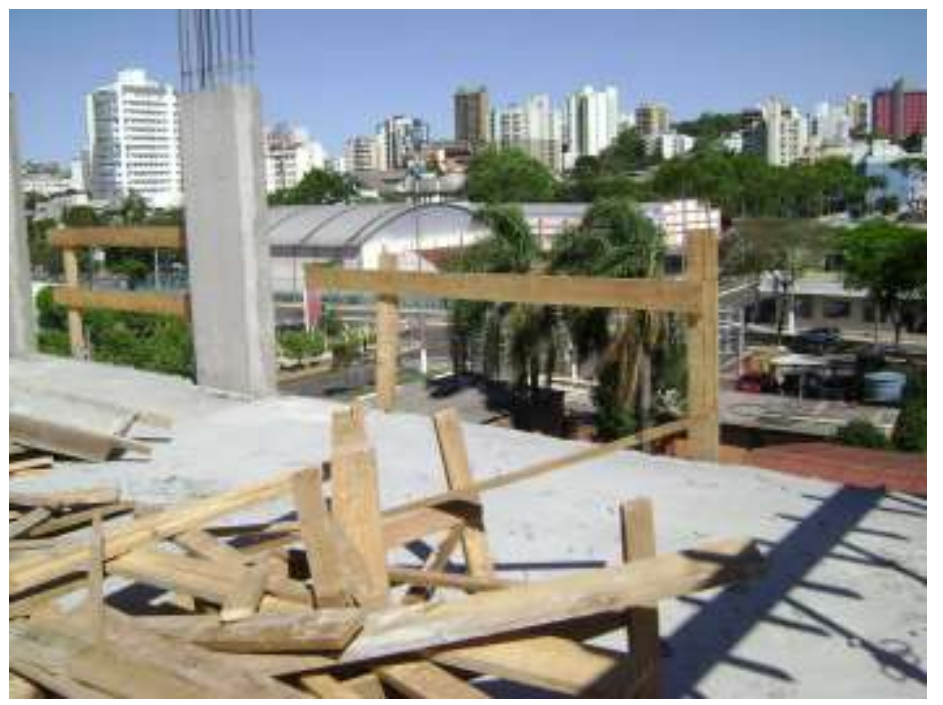


Quadro 1- Nova lista de verificação sugerida para avaliar a adequação de canteiros de obra à NR-18 (Continua)

\begin{tabular}{|c|c|}
\hline \multicolumn{2}{|r|}{ A. PCMAT (Programa de Condições e Meio Ambiente de Trabalho na Indústria da Construção Civil } \\
\hline A.1 & $\begin{array}{l}\text { O PCMAT está disponível na obra? (Obs.: em Chapecó, conforme convenção coletiva de trabalho, exige- } \\
\text { se PCMAT em obras com mais de } 5 \text { trabalhadores. Caso a obra não se enquadre, marque "não se aplica" } \\
\text { para todos os itens). }\end{array}$ \\
\hline A.7 & $\begin{array}{l}\text { Está previsto no PCMAT um programa educativo de prevenção de acidentes e doenças do trabalho, } \\
\text { inclusive com sua carga horária? }\end{array}$ \\
\hline \multicolumn{2}{|r|}{ B. ORDEM, LIMPEZA E TAPUMES } \\
\hline B.1 & $\begin{array}{l}\text { Os tapumes têm altura mínima de } 2,20 \mathrm{~m} \text {, estão construídos e fixados de forma resistente e em bom estado } \\
\text { de conservação? }\end{array}$ \\
\hline B.3 & $\begin{array}{l}\text { O entulho possui local específico para depósito (baia, caçamba tele-entulho ou área do canteiro } \\
\text { delimitada)? }\end{array}$ \\
\hline \multicolumn{2}{|r|}{ C. ÁREAS DE VIVÊNCIA } \\
\hline \multicolumn{2}{|r|}{ C.1 INSTALAÇÕES SANITÁRIAS (Obrigatório para todas as obras) } \\
\hline C.1.1 & $\begin{array}{l}\text { As instalações sanitárias estão em bom estado de conservação, higiene e limpeza, e não se encontram } \\
\text { diretamente ligadas aos locais de refeição? }\end{array}$ \\
\hline C.1.16 & Nos locais onde estão os chuveiros há piso de material antiderrapante ou estrado de madeira? \\
\hline \multicolumn{2}{|r|}{ C.2 LOCAL PARA AS REFEIÇÕES (Obrigatório para todas as obras) } \\
\hline C.2.1 & $\begin{array}{l}\text { Tem fechamento (paredes ou tela) que evite a penetração de pequenos animais e isole a instalação das } \\
\text { áreas de produção e circulação, contribuindo para a manutenção da limpeza do local? }\end{array}$ \\
\hline C.2.10 & Há fornecimento de água potável por meio de bebedouro ou outro sistema no local para refeições? \\
\hline \multicolumn{2}{|r|}{ C.3 VESTIÁRIO (Obrigatório para todas as obras) } \\
\hline C.3.1 & $\begin{array}{l}\text { Está localizado próximo à entrada da obra, está em bom estado de conservação e tem iluminação natural } \\
\text { e/ou artificial? }\end{array}$ \\
\hline C.3.7 & Tem bancos/assentos em número suficiente para atender a todos os trabalhadores da obra? \\
\hline \multicolumn{2}{|r|}{$\begin{array}{l}\text { C.4 FORNECIMENTO DE ÁGUA POTÁ VEL NOS POSTOS DE TRABALHO } \\
\text { (Obrigatório para todas as obras) }\end{array}$} \\
\hline C.4.1 & $\begin{array}{l}\text { Há fornecimento de água potável e refrigerada por meio de bebedouro ou outro sistema que garanta seu } \\
\text { abastecimento nos postos de trabalho? Caso não se use bebedouro, assinale "não se aplica" para os itens } \\
\text { C. } 4.2 \text { e C. } 4.3 \text { e especifique o outro dispositivo: }\end{array}$ \\
\hline C.4.3 & $\begin{array}{l}\text { Para se deslocar do posto de trabalho ao bebedouro todos os trabalhadores fazem deslocamentos inferiores } \\
\text { a } 100 \mathrm{~m} \text { no plano horizontal e inferiores a } 15 \mathrm{~m} \text { no plano vertical? }\end{array}$ \\
\hline \multicolumn{2}{|r|}{ C.5 ALOJAMENTO E ÁREA DE LAZER (Não é obrigatório para todas as obras) } \\
\hline C.5.1 & $\begin{array}{l}\text { Tem parede em alvenaria, madeira ou material equivalente e piso de concreto cimentado, madeira ou } \\
\text { outro material lavável? }\end{array}$ \\
\hline C.5.10 & Havendo alojamento, existe área de lazer (sala de televisão, mesa de jogos, etc.)? Se sim, descreva-a: \\
\hline \multicolumn{2}{|r|}{ D. ESCAVAÇÕES, FUNDAÇÕES E DESMONTE DE ROCHAS } \\
\hline D.1 & $\begin{array}{l}\text { Existe escoramento para muros, edificações vizinhas e todas as estruturas que possam ser afetadas pela } \\
\text { escavação? }\end{array}$ \\
\hline D.5 & Taludes com altura superior a 1,75 m têm sua estabilidade garantida por escoramentos? \\
\hline \multicolumn{2}{|r|}{ E. SERRA CIRCULAR E CENTRAL DE CARPINTARIA } \\
\hline E.1 & $\begin{array}{l}\text { A serra é dotada de mesa estável (em madeira ou metálica) com fechamento em suas faces inferiores, } \\
\text { anterior e posterior, ou seja, as faces frontal e oposta à posição de trabalho? }\end{array}$ \\
\hline E.11 & O canteiro possui extintor de incêndio próximo ao depósito de madeiras? \\
\hline \multicolumn{2}{|r|}{ F. ARMAÇÕES DE AÇO } \\
\hline F.1 & $\begin{array}{l}\text { A bancada de corte e dobra de vergalhões está apoiada sobre superfície resistente, nivelada e não } \\
\text { escorregadia? }\end{array}$ \\
\hline F.8 & Há placa de sinalização junto à bancada de armação de aço, indicando o uso dos EPIs pertinentes? \\
\hline
\end{tabular}


Quadro 1- Nova lista de verificação sugerida para avaliar a adequação de canteiros de obra à NR-18 (Continuação)

\begin{tabular}{|c|c|}
\hline \multicolumn{2}{|r|}{ G. PROTEÇÃO CONTRA QUEDAS DE ALTURA } \\
\hline \multicolumn{2}{|r|}{ G.1 CORRIMÃOS DAS ESCADAS PERMANENTES } \\
\hline G.1.1 & $\begin{array}{c}\text { Os corrimãos, caso sejam de madeira, estão isentos de qualquer pintura que encubra nós e rachaduras } \\
\text { na madeira? }\end{array}$ \\
\hline G.1.4 & Há rodapé com altura de $0,2 \mathrm{~m}$, constituído de madeira ou outro material de resistência equivalente? \\
\hline \multicolumn{2}{|r|}{ G.2 ESCADAS DE MÃO E RAMPAS PROVISÓRIAS } \\
\hline G.2.1 & As escadas, caso sejam de madeira, estão isentas de qualquer pintura que encubra nós e rachaduras? \\
\hline G.2.8 & $\begin{array}{l}\text { As rampas provisórias com inclinação superior a } 18^{\circ} \text { têm peças transversais fixadas a cada } 40 \mathrm{~cm} \text { (no } \\
\text { máximo) para apoio dos pés? }\end{array}$ \\
\hline \multicolumn{2}{|r|}{ G.3 POÇO DO ELEVADOR } \\
\hline G.3.1 & $\begin{array}{l}\text { Os vãos de acesso às caixas de elevadores possuem fechamento provisório do tipo sistema guarda- } \\
\text { corpo e rodapé ou dispositivo que cumpra as mesmas funções de proteção (grade ou painel, por } \\
\text { exemplo)? Caso o dispositivo seja alternativo ao sistema guarda-corpo e rodapé, assinale "não se } \\
\text { aplica" para os itens G.3.3 a G.3.6, e descreva-o: }\end{array}$ \\
\hline G.3.7 & $\begin{array}{l}\text { Existe proteção horizontal em todas as lajes com assoalhamento inteiriço, no mínimo, a cada } 3 \\
\text { pavimentos? }\end{array}$ \\
\hline \multicolumn{2}{|c|}{$\begin{array}{l}\text { G.4 PROTEÇÃO CONTRA QUEDA NO PERÍMETRO DOS PAVIMENTOS - Assinale a(s) situação(ões) } \\
\text { encontradas na obra }\end{array}$} \\
\hline G.4.1 & $\begin{array}{c}\text { Pavimentos com laje de piso e de forro já concretadas sem fechamento de alvenaria. Caso o } \\
\text { dispositivo seja alternativo ao sistema guarda-corpo e rodapé, assinale "não se aplica" para os itens } \\
\text { G.4.1.1 a G.4.1.4 e descreva-o: }\end{array}$ \\
\hline G.4.2 & $\begin{array}{l}\text { Pavimento com laje de piso concretada e execução das fôrmas da laje do pavimento superior. } \\
\text { Caso o dispositivo seja alternativo ao sistema guarda-corpo e rodapé, marque "não se aplica" para os } \\
\text { itens marcados G.4.2.1 a G.4.2.4 e descreva-o: }\end{array}$ \\
\hline G.4.3 & $\begin{array}{l}\text { Pavimento em que estão sendo colocadas as ferragens nas fôrmas de vigas e lajes ou no qual está } \\
\text { sendo feita a concretagem. Caso o dispositivo seja alternativo ao sistema guarda-corpo e rodapé, } \\
\text { marque "não se aplica" para os itens marcados G.4.3.1 a G.4.3.4 e descreva-o: }\end{array}$ \\
\hline \multicolumn{2}{|r|}{ G.5 ABERTURAS NO PISO } \\
\hline H.5.1 & $\begin{array}{c}\text { Todas as aberturas nos pisos de lajes têm fechamento provisório resistente, tais como assoalho fixado } \\
\text { à estrutura de forma a evitar seu deslizamento ou sistema de guarda-corpo e rodapé? }\end{array}$ \\
\hline \multicolumn{2}{|r|}{ G.6 PLATAFORMA DE PROTEÇÃO - Assinale a situação atual da obra } \\
\hline G.6.1 & $\begin{array}{l}\text { A plataforma principal de proteção está na primeira laje situada a, no mínimo, um pé-direito acima do } \\
\text { nível do terreno? Se estiver em outra indique: }\end{array}$ \\
\hline G.6.9 & Existe fechamento com tela entre as extremidades das plataformas de proteção? \\
\hline \multicolumn{2}{|r|}{ G.7 ANDAIMES SUSPENSOS } \\
\hline G.7.1 & $\begin{array}{l}\text { Os andaimes suspensos dispõem de sistema de guarda-corpo e rodapé, com tela de arame galvanizado } \\
\text { (ou material de resistência e durabilidade equivalentes), em todo o perímetro, exceto na face de } \\
\text { trabalho? }\end{array}$ \\
\hline G.7.7 & $\begin{array}{l}\text { Os andaimes suspensos possuem placa de identificação em local visível constando a carga máxima de } \\
\text { trabalho permitida? }\end{array}$ \\
\hline \multicolumn{2}{|r|}{ G.8 ANDAIMES SIMPLESMENTE APOIADOS } \\
\hline G.8.1 & $\begin{array}{l}\text { O apoio do andaime está sobre sapata em base sólida e nivelada capaz de resistir aos esforços } \\
\text { solicitantes e às cargas transmitidas? }\end{array}$ \\
\hline G.8.4 & $\begin{array}{l}\text { Quando externos e com altura superior a 2,0 m, a estrutura dos andaimes está fixada à construção por } \\
\text { meio de amarração e estroncamento? }\end{array}$ \\
\hline \multicolumn{2}{|r|}{ G.9. CADEIRAS SUSPENSAS } \\
\hline G.9.1 & $\begin{array}{l}\text { A cadeira suspensa tem dispositivo de subida e descida com dupla trava de segurança e sistema de } \\
\text { fixação do trabalhador por meio de cinto de segurança? }\end{array}$ \\
\hline G.9.5 & A cadeira suspensa é sustentada por cabo de aço ou fibra sintética? \\
\hline
\end{tabular}


Quadro 1- Nova lista de verificação sugerida para avaliar a adequação de canteiros de obra à NR-18 (Continuação)

\begin{tabular}{|c|c|}
\hline \multicolumn{2}{|c|}{$\begin{array}{l}\text { G.10 ANCORAGEM (Obrigatória previsão de instalação de dispositivos destinados à ancoragem de equipamentos } \\
\text { de sustentação de andaimes e de cabos de segurança para o uso de proteção individual em edificações com, no } \\
\text { mínimo, } 4 \text { pavimentos ou altura de } 12 \mathrm{~m} \text {, a partir do nível térreo, com a finalidade da utilização nos serviços de } \\
\text { limpeza, manutenção e restauração de fachadas) }\end{array}$} \\
\hline G.10.1 & Os pontos de ancoragem estão dispostos de modo a atender a todo o perímetro da edificação? \\
\hline G.10.2 & $\begin{array}{c}\text { Os pontos são constituídos de material resistente a intempéries (aço inoxidável ou material } \\
\text { equivalente)? }\end{array}$ \\
\hline \multicolumn{2}{|r|}{ H. ELEVADORES } \\
\hline \multicolumn{2}{|r|}{$\begin{array}{l}\text { H.1 ELEVADOR DE CREMALHEIRA - Plataforma do elevador de cremalheira (próprio para transporte de } \\
\text { passageiros e de cargas) }\end{array}$} \\
\hline H.1.1 & Há a disposição na obra manual de orientação do fabricante do elevador de cremalheira? \\
\hline H.1.9 & $\begin{array}{l}\text { O elevador é dotado de amortecedor de impacto de velocidade caso este ultrapasse o limite de parada } \\
\text { final? }\end{array}$ \\
\hline \multicolumn{2}{|r|}{ H.2 ELEVADOR A CABO } \\
\hline \multicolumn{2}{|c|}{$\begin{array}{l}\text { H.2.1 ELEVADOR DE PASSAGEIROS (Obrigatório para edifícios com mais de } 8 \text { pavimentos. Caso a obra não } \\
\text { disponha desse tipo de elevador, responda "não" para os itens H.2.1.1 a H.2.1.8) }\end{array}$} \\
\hline H.2.1.1 & $\begin{array}{l}\text { Existe um interruptor nos fins de curso superior e inferior, conjugado com freio automático } \\
\text { eletromecânico? }\end{array}$ \\
\hline H.2.1.8 & $\begin{array}{l}\text { Caso o elevador de passageiro seja utilizado para transporte de materiais não simultâneo, tem } \\
\text { sinalização por meio de cartazes em seu interior em que conste de forma visível os seguintes dizeres: } \\
\text { "É PERMITIDO O USO DESTE ELEVADOR PARA TRANSPORTE DE MATERIAL, DESDE } \\
\text { QUE NÃO REALIZADO SIMULTANEAMENTE COM O TRANSPORTE DE PESSOAS”? }\end{array}$ \\
\hline \multicolumn{2}{|r|}{ H.2.2 ELEVADOR DE CARGA } \\
\hline \multicolumn{2}{|r|}{ H.2.2.1 TORRE DO ELEVADOR } \\
\hline \multicolumn{2}{|r|}{ A torre está afastada das redes elétricas ou está isolada? } \\
\hline H.2.2.1.18 & $\begin{array}{l}\text { As rampas de acesso à torre são fixadas na estrutura do prédio e da torre, possuem guarda-corpo e } \\
\text { rodapé completos, têm piso antiderrapante e inclinação ascendente no sentido de entrada? }\end{array}$ \\
\hline \multicolumn{2}{|r|}{ H.2.2.2 PLATAFORMA DO ELEVADOR } \\
\hline H.2.2.2.1 & O elevador (cabin \\
\hline H.2.2.2.5 & $\begin{array}{c}\text { O elevador tem dispositivo de tração na subida e descida, de modo a impedir a descida da cabina em } \\
\text { queda livre (banguela)? }\end{array}$ \\
\hline \multicolumn{2}{|r|}{ H.3 POSTO DO GUINCHEIRO } \\
\hline H.3.1 & O posto de trabalho do guincheir \\
\hline H.3.5 & Existe extintor de incêndio de pó qu \\
\hline \multicolumn{2}{|r|}{ I. GRUA } \\
\hline I.1 & $\begin{array}{l}\text { A ponta da lança e o cabo de aço de sustentação estão afastados, no mínimo, } 3,0 \mathrm{~m} \text { de qualquer } \\
\text { obstáculo e tem afastamento da rede elétrica? }\end{array}$ \\
\hline I.14 & A grua possui luz de obstáculo e trava de segurança no gancho do moitão? \\
\hline \multicolumn{2}{|r|}{ J. SERVIÇOS EM TELHADO E COBERTURA } \\
\hline J.1 & $\begin{array}{l}\text { Nos serviços em telhados, há cabo guia ou cabo de segurança para fixação de mecanismo de ligação } \\
\text { por talabarte acoplado ao cinto de segurança do tipo paraquedista, para movimentação segura do } \\
\text { trabalhador? }\end{array}$ \\
\hline $\mathbf{J} .3$ & Existe sinalização de advertência e isolamento da área? \\
\hline \multicolumn{2}{|r|}{ K. INSTALAÇÕES ELÉTRICAS } \\
\hline K.1 & $\begin{array}{l}\text { Na obra não existem circuitos e equipamentos elétricos com partes vivas expostas, tais como fios } \\
\text { desencapados? }\end{array}$ \\
\hline K.7 & $\begin{array}{l}\text { Caso necessário, as redes de alta tensão estão isoladas, de modo a evitar contatos acidentais com } \\
\text { veículos, equipamentos e trabalhadores? }\end{array}$ \\
\hline \multicolumn{2}{|r|}{ L. MÁQUINAS, EQUIPAMENTOS E FERRAMENTAS DIVERSAS } \\
\hline L.1 & $\begin{array}{c}\text { Todas as partes móveis dos motores, transmissões e partes perigosas das máquinas estão protegidas } \\
\text { do alcance dos trabalhadores? }\end{array}$ \\
\hline L.9 & $\begin{array}{l}\text { As ferramentas pneumáticas possuem dispositivo de partida instalada, de modo a reduzir seu } \\
\text { acionamento acidental? }\end{array}$ \\
\hline
\end{tabular}


Quadro 1- Nova lista de verificação sugerida para avaliar a adequação de canteiros de obra à NR-18 (Continuação)

\begin{tabular}{|c|c|}
\hline \multicolumn{2}{|r|}{ M. EQUIPAMENTOS DE PROTEÇÃO INDIVIDUAL (EPI) } \\
\hline M.1 & São fornecidos capacetes para os visitantes? \\
\hline M.6 & $\begin{array}{l}\text { Há alertas quanto à obrigatoriedade do uso dos EPIs básicos (capacete e botina) dispostos em locais } \\
\text { de fácil visualização ou de presença obrigatória dos operários (refeitórios, vestiários, alojamentos)? }\end{array}$ \\
\hline \multicolumn{2}{|r|}{ N. ARMAZENAMENTO E ESTOCAGEM DE MATERIAIS } \\
\hline N.1 & $\begin{array}{c}\text { O cimento é estocado em pilhas de, no máximo, } 10 \text { sacos, de forma a facilitar seu manuseio (a NR-18 } \\
\text { não estabelece altura-limite)? }\end{array}$ \\
\hline N.8 & O canteiro possui extintor de incêndio próximo ao almoxarifado? \\
\hline \multicolumn{2}{|r|}{ O. PROTEÇÃ̃O CONTRA INCÊNDIO } \\
\hline 0.1 & O canteiro possui extintor de incêndio próximo à serra elétrica? \\
\hline 0.5 & O canteiro possui equipes de operários treinadas para o primeiro combate ao fogo? \\
\hline \multicolumn{2}{|r|}{ P. SINALIZAÇÃO DE SEGURANÇA } \\
\hline P.1 & $\begin{array}{c}\text { Há identificação dos locais de apoio (banheiros, escritório, almoxarifado, etc.) que compõem o } \\
\text { canteiro? }\end{array}$ \\
\hline P.8 & Há placa identificando acessos, circulação de veículos e equipamentos na obra? \\
\hline
\end{tabular}

\section{Proposta de uma nova lista de verificação para a NR-18}

Acredita-se que a utilização de uma lista de verificação seja uma importante ferramenta para avaliar os canteiros de obra. Trata-se de uma medida proativa para assegurar ambientes de trabalho seguros e consequentemente prevenir acidentes. Na busca de aprimorar essa alternativa é que foram feitas modificações e adaptações na lista de verificação sugerida por Costella e Galina (2010), tentando adequá-laà realidade das obras de nosso país e às novas portarias da NR-18.

Em virtude do fato de a nova lista de verificação ser extensa, não é possível apresentar aqui todos os itens e, dessa forma, no Quadro 1 são exibidos apenas o primeiro e o último item de cada seção da lista, sem as opções de resposta (SIM, NÃO e NÃO SE APLICA).

Cabe salientar que a utilização da lista de verificação para avaliação do cumprimento da NR18 possui limitações, conforme já apontado por Cambraia e Formoso (2011). As limitações consistem em avaliar mais de um aspecto em cada pergunta, por conta de diminuir o número, já extenso, de itens; consistem somente na avaliação visual dos itens, sem qualquer tipo de ensaio ou verificação técnica; não apresentam pontuação relativa entre os itens, isso em função do número elevado de itens a serem atendidos pela NR-18; também não analisam os resultados por meio de análises estatísticas sofisticadas; por fim, a lista de verificação apresenta um caráter prescritivo, tal qual o da NR-18, ou seja, não analisa os aspectos gerenciais.

\section{Considerações finais}

Devido ao caráter temporário das instalações de produção e, em decorrência disso, das dificuldades em fiscalizar e adotar medidas preventivas estáveis, das peculiaridades de cada obra, da alta rotatividade da mão de obra, do emprego de mão de obra terceirizada e da falta de técnicos especializados dentro das empresas, é difícil projetar e manter ambientes seguros. Na maioria dos casos, durante os questionamentos relativos à aplicação da lista de verificação nos canteiros de obras, observou-se que os principais envolvidos nas obras (engenheiro, mestre de obra, encarregado, etc.) não possuem conhecimento detalhado das exigências da NR-18; sendo assim, é preciso instruí-los e conscientizá-los da importância disso.

Apesar dos elevados riscos presentes nos ambientes de trabalho do setor da construção civil, ficou evidenciado que existem diversos canteiros de obra em que as condições de trabalho ofertadas não são exemplares. Assim, a segurança na construção civil ainda está aquém do esperado, e a importância a ela dada fica em segundo plano. Nesse contexto, como opina Rocha (1999), cumprir com as exigências daNR-18 é o primeiro passo para se atingirem metas maiores.

Os resultados da avaliação do cumprimento da NR-18 em função do porte de cada obra residencial, inédita, permitiram observar as melhores condições de trabalho dos canteiros de grande porte, ficando estes com média geral de 6,47 , enquanto as obras médias obtiveram nota 4,56, e as de pequeno porte, somente 1,97. Assim 
ficou evidenciado o descaso com a segurança do trabalho nos canteiros de pequeno porte, como Cheng et al. (2010) relataram em sua pesquisa, na qual as pequenas empresas não possuíam habilidades gerenciais de SST e, consequentemente, havia baixa valorização dos trabalhadores.

Em relação à nova proposta de lista de verificação, que se encontra atualizada em relação às últimas portarias de alteração da NR-18,destaca-se que a modificação de alguns itens e a adaptação destes à realidade das obras contribuiu para avaliar as condições de cumprimento da NR-18 nos canteiros, independentemente de seu tamanho.

\section{Referências}

ABUDAYYEH, O. et al.An Investigation of Management's Commitment to Construction Safety.International Journal of Project Management, v. 24, n. 2, p. 167-174, 2006.

AKSORN, T.; HADIKUSUMO, B. H. W. Critical Success Factors Influencing Safety Program Performance in Thai Construction Projects. Safety Science, v. 46, n. 4, p. 709-727, 2008.

ALVARENGA, F. C. Verificação da Aplicação da NR-18 nos Canteiros de Obra da Cidade de Belém/PA.Belém, 2009. Trabalho de Conclusão de Curso (Graduação) -Faculdade de Engenharia Civil, Universidade Federal do Pará, Belém, 2009.

BRASIL. Ministério do Trabalho e Emprego. NR6: Equipamento de Proteção Individual. Brasília: MTE, 2011a.

BRASIL. Ministério do Trabalho e Emprego. NR18: condições e meio ambiente de trabalho na indústria da construção. Brasília: MTE, 2013a.

BRASIL. Ministério do Trabalho e Emprego. Secretaria de Inspeção do Trabalho. Portaria $\mathrm{N}^{\circ}$ 201, de 21 de janeiro de 2011.Diário Oficial da União, DF, 24 de janeiro de 2011b.

BRASIL. Ministério do Trabalho e Emprego. Secretaria de Inspeção do Trabalho. Portaria $N^{\circ}$ 224, de 06 de maio de 2011.Diário Oficial da União, DF, 08 de maio de 2011c.

BRASIL. Ministério do Trabalho e Emprego. Secretaria de Inspeção do Trabalho. Portaria N ${ }^{\circ}$ 237, de 10 de junho de 2011. Diário Oficial da União, DF, 13 de junho de $2011 \mathrm{~d}$.

BRASIL. Ministério do Trabalho e Emprego. Secretaria de Inspeção do Trabalho. Portaria $N^{\circ}$ 254, de 04 agosto de 2011.Diário Oficial da União, DF, 08 de agosto de 2011e.
BRASIL. Ministério do Trabalho e Emprego. Secretaria de Inspeção do Trabalho. Portaria $N^{\circ}$ 296, de 16 de dezembro de 2011.Diário Oficial da União, DF, 19 de dezembro de $2011 \mathrm{f}$.

BRASIL. Ministério do Trabalho e Emprego. Secretaria de Inspeção do Trabalho. Portaria N ${ }^{\circ}$ 318, de 08 de maio de 2012. Diário Oficial da União, DF, 09 de maio de 2012.

BRASIL. Ministério do Trabalho e Emprego. Secretaria de Inspeção do Trabalho. Portaria N ${ }^{o}$ 644, de 09 de maio de 2013.Diário Oficial da União, DF, 10 de maio de 2013b.

CAMBRAIA, F. B.; FORMOSO, C. T. Análise de Avanços e Retrocessos no Atendimento às Especificações da NR-18 nos Últimos Dez Anos. In: SIMPÓSIO BRASILEIRO DE GESTÃO E ECONOMIA DA CONSTRUÇÃO, 7., Belém, 2011. Anais... Belém: ANTAC, 2011.

CAMINO LÓPEZ, M. A. et al.Construction Industry Accidents in Spain.Journal of Safety Research, v. 39, n. 5, p. 497-507, 2008.

CHAGAS, F. M. S. Avaliação do Atendimento aos Requisitos da NR 18 em Canteiros de Obras da Cidade de Aracaju/Sergipe. Aracaju, 2009. Trabalho de Conclusão de Curso (Graduação) Departamento de Engenharia Civil, Universidade Federal de Sergipe, Aracaju, 2009.

CHENG, C. W. et al.Characteristic Analysis of Occupational Accidents at Small Construction Enterprises. Safety Science, v. 48, n. 6, p. 698707, 2010.

COSTELlA, M. F.; GALINA, M. Proposta de Revisão e Atualização de Lista de Verificação da NR-18. In: ENCONTRO NACIONAL DE TECNOLOGIA DO AMBIENTE CONSTRUÍDO, 13., Canela, 2010. Anais...Porto Alegre: ANTAC, 2010.

FABIANO, B.; CURRÒ, F.; PASTORINO, R. A Study of the Relationship BetweenOccupational Injuries and Firm Size and Type in the Italian Industry. Safety Science, v. 42, n. 7/8, p. 587-600, 2004.

FERNÁNDEZ-MUÑIZ, B.; MONTES-PEÓN, J. M.; VÁZQUEZ-ORDÁS, C. J. Relation BetweenOccupational Safety Management and Firm Performance. Safety Science, v. 47, n. 7, p. 980-991, 2009.

GAMBATESE, J.; BEHM, M.; RAJENDRAN, S. Design's Role in Construction Accident Causality and Prevention: perspectives from an expect panel. Safety Science, v. 46, n. 4, p. 675-691, 2008. 
GONÇALVES, E. A. Manual de Segurança e Saúde no Trabalho.4. ed. São Paulo: LTR, 2008.

HINZE, J.; GAMBATESE, J. Factors That Influence Safety Performance of Specialty Contractors. Journal of Construction Project and Management, v. 129, n. 2, p. 159-164, 2003.

HINZE, J; PEDERSEN, C.; FREDLEY, J. Identifying Root Causes of Construction Injuries.Journal of Construction Project and Management, v. 124, n. 1, p. 67-71, 1998.

HINZE, J.; THURMAN, S.; WEHLE, A. Leading Indicators of Construction Safety

Performance.Safety Science, v. 51, n. 1, p. 23-28, 2013.

HUANG, X.; HINZE, J. Analysisof Construction Worker Fall Accidents.Journal of Construction Project and Management, v. 129, n. 3, p. 262271, 2003.

LING, F. Y. Y.; LIU, M.; WOO, Y. C. Construction Fatalities in Singapore.

International Journal of Project Management,v. 27, n. 7, p. 717-726, 2009.

MALlmANN, B. S. Avaliação do Atendimento aos Requisitos da NR-18 em Canteiros de Obra.Porto Alegre, 2008. Trabalho de Conclusão de Curso (Graduação em Engenharia Civil) Departamento de Engenharia Civil, Universidade Federal do Rio Grande do Sul, Porto Alegre, 2008.

MCVITTIE, D.; BANIKIN, H.;

BROCKLEBANK, W.The Effects of Firm Size on Injury Frequency in Construction.Safety Science, v. 27, n. 1, p. 19-23, 1997.

NIZA, C.; SILVA, S.; LIMA, M.L. Occupational Accident Experience:association with workers' accident explanation and definition. Safety Science, v. 46, n. 4, p. 959-971, 2008.
PANDOLFO, A. et al. Diagnóstico do Conhecimento, Percepção e Aplicação da NR-18 em Obras de Construção Civil na Cidade de Marau-RS. In: SIMPÓSIO BRASILEIRO DE GESTÃO E ECONOMIA DA CONSTRUÇÃO, 5., Campinas, SP, 2007.

Anais...Campinas:ANTAC, 2007.

ROCHA, C. A. G. S. C. Diagnóstico do Cumprimento da NR-18 no Subsetor Edificações da Construção Civil e Sugestões Para Melhorias.Porto Alegre, 1999.Dissertação (Mestrado em Engenharia Civil) - Programa de Pós-Graduação em Engenharia Civil, Universidade Federal do Rio Grande do Sul, Porto Alegre, 1999.

SAURIN, T. A.; LANTELME, E.; FORMOSO, C. T. Contribuições Para Aperfeiçoamento da NR18: condições e meio ambiente de trabalho na indústria da construção. Relatório de Pesquisa. Porto Alegre: Universidade Federal do Rio Grande do Sul, 2000.

SAURIN, T. A. Método Para Diagnósticos e Diretrizes Para Planejamento de Canteiros de Obra de Edificações. Porto Alegre, 1997.Dissertação (Mestrado em Engenharia Civil) - Programa de Pós-Graduação em Engenharia Civil, Universidade Federal do Rio Grande do Sul, Porto Alegre, 1997.

SAWACHA, E.; NAOUM, S.; FONG, D. Factors Affecting Safety Performance on Construction Sites.International Journal of Project Management, v. 17, n. 5, p. 309-315, 1999.

WAEHRER, G. M. et al. Costs of Occupational Injuries in Construction in the United States. Accident Analysis and Prevention, v. 39, n. 6, p. 1258-1266, 2007.

\section{Agradecimento}

Este estudo é parte integrante de projeto financiado pelo Convênio Pibic/Fape com o Programa de PósGraduação em Tecnologia e Gestão da Inovação da Universidade Comunitária da Região de Chapecó (Unochapecó). 


\section{Marcelo Fabiano Costella}

Programa de Pós-graduação em Tecnologia e Gestão da Inovação | Universidade Comunitária da Região de Chapecó | Rua Barão do Rio Branco, 611-D/101, Centro | Chapecó - SC - Brasil | CEP 89801-030 | Tel.: (49) 9982-4808 | E-mail: costella@unochapeco.edu.br

\section{Franciele Cristina Junges}

Programa de Pós-graduação em Tecnologia e Gestão da Inovação | Universidade Comunitária da Região de Chapecó | Avenida Atilio Fontana, 591-E, Efapi | Chapecó - SC - Brasil | CEP 89809-000 | Tel.: (49) 3321-8290 | E-mail: franci_fcj@unochapeco.edu.br

\section{Silvio Edmundo Pilz}

Programa de Pós-graduação em Tecnologia e Gestão da Inovação | Universidade Comunitária da Região de Chapecó | Rua Clevelândia, 410-D, Centro | Chapecó - SC - Brasil | CEP 89802-410 | Tel.: (49) 3322-1794 | E-mail: silvio@unochapeco.edu.br

\section{Revista Ambiente Construído}

Associação Nacional de Tecnologia do Ambiente Construído

Av. Osvaldo Aranha, $99-3^{\circ}$ andar, Centro

Porto Alegre - RS - Brasil

CEP $90035-190$

Telefone: +55 (51) 3308-4084

Fax: +55 (51) 3308-4054

www.seer.ufrgs.br/ambienteconstruido

E-mail: ambienteconstruido@ufrgs.br

102 Costella, M. F.; Junges, F. C.; Pilz, S. E. 